\title{
WETTABILITY AND SURFACE ROUGHNESS CHARACTERISTICS OF MEDIUM DENSITY FIBERBOARD PANELS FROM RHODODENDRON (RHODODENDRON PONTICUM) BIOMASS
}

\author{
Mehmet Akgül', Süleyman Korkut ${ }^{1 \star}$, Osman Çamlıbel ${ }^{2}$, Zeki Candan ${ }^{3}$, Turgay Akbulut ${ }^{3}$
}

\begin{abstract}
Wettability and surface roughness properties of medium density fiberboard (MDF) panels made from Rhododendron biomass were examined in this study. Rhododendron dominates the understory layer of the forests throughout the Black Sea Region in Turkey with substantial biomass potential. This study was conducted to evaluate suitability of Rhododendron fiber for MDF production. For the experiments, rhododendron and commercially-manufactured-chip (Pinus sylvestris L. and Quercus robur L.) with $11 \%$ moisture content were used. The mixing ratios of rhododendron with commercially-manufactured-chip were 100:0, 75:25, 50:50, 25:75 and 0:100\%, respectively. Commercial urea formaldehyde (UF) adhesive was used as a binder. A stylus method was employed to evaluate the surface characteristics of the samples. Roughness measurements by the stylus method were taken perpendicularly to the fiber. There was a significant difference $(\mathrm{p}=0.05)$ between surface roughness parameters $\left(R_{a}, R_{z}, R_{q}\right.$, and $\left.R_{y}\right)$. The results obtained in this study revealed that all the panels have met the general purpose-use requirements of European Norm (EN). It was found that panels made with a 25/75 ratio of rhododendron to commercially-manufactured-chip had a significantly lower contact angle $\left(88.14^{\circ}\right)$ than panels made with a $100 / 0$ ratio $\left(117.91^{\circ}\right)$. Surface roughness measurements are based on four roughness parameters, average roughness $\left(R_{a}\right)$, mean peak-to-valley height $\left(\mathrm{R}_{\mathrm{z}}\right)$, root mean square roughness $\left(\mathrm{R}_{\mathrm{q}}\right)$, and maximum peak-to-valley height $\left(R_{y}\right)$ were considered to evaluate the surface characteristics of the panels and supported the above findings as the panels made with a 25/75 ratio had a slightly rougher surface with average values of $2.929 \mu \mathrm{m}\left(\mathrm{R}_{\mathrm{a}}\right)$. From the tests performed, we conclude that increasing the rhododendron mixing portion increased surface roughness and decreased wettability. Based on these results, rhododendron biomass could be an alternative raw material for MDF manufacturing.
\end{abstract}

Keywords: Rhododendron, MDF, surface roughness, wettability, surface characteristics.

\section{INTRODUCTION}

The demand for wood in the forest industry has been growing, but the production of industrial wood from natural forests continues to decline. The decline in forest resources in developing countries is due to depletion of the resources while in developed countries it is due to the conversion of forested areas from industrial production to other uses such as recreation. A significant pressure on standing forest resources on the other hand, results in higher demand for wood in the forest industry due to increasing population and new application areas (Akgul and Tozluoglu 2008).

Because of a continuing lack of raw material in the forest products industry, medium density fiberboard (MDF) production and other sectors are being negatively affected. The current trend is for fiberboard manufacturers to use wastes as raw material. Additionally, there is a need to find

\footnotetext{
${ }^{1}$ Department of Forest Industry Engineering, Faculty of Forestry, Duzce University, 81620, Duzce-Turkey.

${ }^{2}$ Divapan Integrated Wood Company, Duzce-Turkey.

${ }^{3}$ Department of Forest Products Engineering, Faculty of Forestry, Istanbul University, Sariyer, 34473, Istanbul, Turkey.

Corresponding author: suleymankorkut@duzce.edu.tr

Received: 22.10.2011 Accepted: 17.03.2012.
} 
alternative raw materials or use wood resources more completely including harvesting residues, barks, annual plants, lumber and furniture plant residues, residues of pulp plants, and recycled paper etc. (Akgul and Camlibel 2008).

Turkish forestry is based mainly on wood production. The most significant part of the forestlands in Turkey is located in the Black Sea Region. Rhododendron (Rhododendron ponticum L.), with about 40 metric ton ha ${ }^{-1}$ biomass (Yildiz et al. 2005), has invaded the understory layer of the forest ecosystem throughout and has become the dominant species in the understory of forests in the Black Sea Region of Turkey (Esen et al. 2006, Akgul et al. 2008).

Medium density fiberboard (MDF) is one of the most rapidly growing composite panel products in the forest products market (Ayrılmış 2008). MDF is a dry formed panel product manufactured from lignocellulosic fiber. While MDF is a relatively new product in Turkey, its production has been increasing in recent years. Turkey has produced more than 4.5 million cubic meters of annually, the 2nd largest MDF production capacity in Europe (FAO, 2009). MDF is used extensively in factoryassembled and ready-to-assemble furniture, as well as in cabinets, underlayment, drawer fronts, molding, and countertops due to its ability to be produced in molded form, as well as in straightedged flat panels.

Data on the chemical composition of wood material is generally preferred and required for many processes and applications in the wood industry (Fengel and Wegener 1989). Species of origin has been considered a major variable in the manufacture of MDF with the density of the species being the most influencing factor (Xu et al. 1998).

Birch (Betula), ash (Fraxinus), lime (Tilia), Douglas-fir (Pseudotsuga), spruce (Picea), and larch (Larix) have been recognized as high quality material for MDF production (Chow et al. 1992). In Turkey, low quality oak, beech, and pine are used either as a single species or as a mixture of raw materials for MDF manufacture (Akbulut et al. 2000). In addition, a study with oak (Ouercus robur L.) showed that production of MDF from oak biomass is technically feasible, but supply of raw materials cannot meet the industry demand as is the case for the other wood industries.

Surface roughness of the substrate is very important when the panels are to be coated with thin overlays such as melamine impregnated papers, foils, and thin films. Roughness refers to the minute and periodic irregularities on the surface other than those defects resulting from the manufacturing techniques (Hiziroglu 2005). Any surface irregularities on the substrate may show through the overlay and influence the quality of final products.

The surface of wood products may be characterized by either topography or profile. Profiles are more widely used in evaluating surface irregularities due to the less-expensive data acquisition equipment required for profile measurement compared to topography measurements. Stylus technique is one of several methods, such as pneumatic, laser, and acoustic emission, that is accurate, practical, and repeatable (Hiziroglu 1996, Stumbo 1963). Quantitative roughness parameters can be accurately calculated from the graph obtained from the surface and all standard parameters can be generated to gather objective information about the surface measured (Goker et al. 1997). Different techniques including stylus method were used in various studies to measure and quantify surface characteristics of wood and wood-based panels (Stumbo 1963, Peters and Cumming 1970, Peters and Mergen 1971).

Wettability and surface roughness properties of wood and wood composite panels produced with 100\% wood materials were previously investigated by Aydin and Colakoglu (2002), Aydin (2004), Aydin et al. (2006), Hiziroglu and Suzuki (2007), Dundar et al. (2008), Ayrılmış et al. (2009), Buyuksari et al. (2010), Candan et al. (2010), Candan et al. (2012), Unsal et al. (2010), Unsal et al. (2011). 
Wettability is defined as a surface condition that determines how fast a liquid will wet and spread on the surface or be repelled. Wettability is crucial for good adhesion in wood bonding. The adhesive has to wet, flow, and penetrate the cellular structure of wood in order to establish intimate contact between molecules of wood and adhesive. The wettability of wood can be characterized by contact angle analysis. This analysis is important to determine the adhesive and coating properties of wood and wood-based composite surfaces. Wetting quality of wood is influenced by many factors including wood macroscopic characteristics (e.g., porosity, surface roughness, wood surface polarity, $\mathrm{pH}$ value, moisture content, grain orientation, and extractives), surface quality of wood (e.g., virgin, aging, and contamination), processing temperature, and properties of adhesives (e.g., acidity, rheology, and viscosity) (Lu 2003). The objectives of this study include (1) Determine surface roughness and wettability properties of the panels made from rhododendron wood and compare them with conventional mixtures (oak and pine) for possible usage for MDF production, and (2) to recommend the result of the experiment to the industry. Therefore, the aim of the current study is to find alternative raw materials for the MDF industry in Turkey.

\section{EXPERIMENTAL}

\section{Materials}

The material for this study included rhododendron wood biomass obtained from forests in the western Black Sea Region of Turkey, and commercially-manufactured-chip (Pinus sylvestris L and Quercus robur $\mathrm{L}$ ).

Rhododendron wood and commercially-manufactured-chip were divided into pieces to make chips of $20 \mathrm{~mm} \times 25 \mathrm{~mm} \times 5 \mathrm{~mm}$. In order to convert the materials into fiber an Asplund defibrator using 7.8 bar of steam pressure at $175{ }^{\circ} \mathrm{C}$ was used for 3.5 minutes. Then, $1 \%$ wax, $0.8 \% \mathrm{NH}_{4} \mathrm{Cl}$ (catalyst), and $11 \%$ urea-formaldehyde (UF) resin (binder) were added into the fiber mixture. Mats with $11 \%$ average moisture content were pressed under $38 \mathrm{~kg} \mathrm{~cm}^{-2}$ pressure at $175^{\circ} \mathrm{C}$ for 4 minutes. After cooling, the panels were sanded using 50, 80 and 120 grit size sandpaper. Then, the panels were conditioned at $20 \pm 2{ }^{\circ} \mathrm{C}$ and $65 \pm 5 \%$ relative humidity (RH) until they reached $12 \%$ moisture content.

Eight experimental panels with dimensions of $2100 \mathrm{~mm}$ by $4900 \mathrm{~mm}$ by $18 \mathrm{~mm}$ with target densities of $0.73 \mathrm{~g} / \mathrm{cm}^{3}$ for each type of raw material combination were manufactured at Divapan Integrated Wood Products Inc. in Duzce, Turkey. Five different ratios of two fiber types, namely 75 \%, $50 \%, 25 \%$ rhododendron fibers were mixed with oak and pine to manufacture the panels. In addition, panels were produced entirely from each species.

\section{Methods}

The TS EN 326-1 (1999) standards were used for preparing the samples from the panels. Each panel was first divided into pieces bigger than $800 \mathrm{~mm}$ by $1600 \mathrm{~mm}$. Then sub-samples were taken from these as per the standard cited above. Following TS EN 325 (1999) standards, sample thickness and length were measured using a digital micrometer and compass grading $0.01 \mathrm{~mm}$.

\section{Determination of surface roughness}

Forty samples were measured from each group. Surface roughness of the samples was measured using a profilometer (Mitutoyo Surftest SJ-301) with the profile method using a stylus device standard. 
Four roughness parameters, mean arithmetic deviation of profile $\left(\mathrm{R}_{\mathrm{a}}\right)$, mean peak to-valley height $\left(R_{z}\right)$, root mean square roughness $\left(R_{q}\right)$, and maximum roughness $\left(R_{y}\right)$ were commonly used in previous studies to evaluate surface characteristics of wood and wood composites such as veneer (Stumbo 1963). $\mathrm{R}_{\mathrm{a}}$ is the average distance from the profile to the mean line over the length of assessment. $\mathrm{R}_{\mathrm{q}}$ is the square root of the arithmetic mean of the squares of profile deviations from the mean line. $\mathrm{R}_{\mathrm{z}}$ can be calculated from the peak-to-valley values of five equal lengths within the profile while maximum roughness $\left(\mathrm{R}_{\mathrm{y}}\right)$ is the distance between peak and valley points of the profile which can be used as an indicator of the maximum defect height within the assessed profile (Mummery 1993). Therefore, such parameters which are characterized by ISO 4287 (1997) and DIN 4768 (1990) were recorded.

Specification of roughness parameters is described by Hiziroglu (1996) and Hiziroglu and Graham (1998). Roughness values were measured with a sensitivity of $0.5 \mu \mathrm{m}$. The length of scanning line $(L \mathrm{t})$ was $15 \mathrm{~mm}$ and the cutoff was $\lambda=2.5 \mathrm{~mm}$. The measuring force of the scanning arm on the surfaces was $4 \mathrm{mN}(0.4 \mathrm{~g})$, which did not significantly damage the surface according to the Mitutoyo Surftest SJ-301 user manual (Mitutoyo surface roughness tester 2002). The points of roughness measurement were randomly marked on the surface of the samples. Measurements were made perpendicular to the fiber of the samples. Measurements were repeated whenever the stylus tip fell into the cell lumen during the tests. Measurements were performed at room temperature and the pin was calibrated before the tests.

\section{Determination of wettability}

Contact angle (CA) tests were performed to evaluate the wettability characteristics of the MDF panels made from rhododendron biomass used in this study. The contact angle value was defined as the angle through the liquid phase formed between the surface of a solid and the line tangent to the droplet radius from the point of contact with the solid.

CA values were obtained by using a goniometer system connected with a digital camera and computer system (KSV Instrument, Finland). The liquid employed for the measurements was $5 \mu \mathrm{L}$ distilled water at $20^{\circ} \mathrm{C}$ with a surface tension of $72.80 \mathrm{mN} / \mathrm{m}$. The CA was determined for each image by digital image analysis software. The image was captured immediately after the droplet of distilled water was placed on the surface, and then every 1 second for the duration of 30 seconds. The mean CA value for each sample was calculated from thirty photo images. A total of fifty testing samples, ten samples for each panel group, were used for the CA analysis.

\section{Statistical Analyses}

For the surface roughness and wettability all multiple comparisons were first subjected to an analysis of variance (ANOVA) at $\mathrm{p}<0.05$ and significant differences between mean values of the mixed of rhododendron and industrial furnish groups were determined using Duncan's multiple range test.

\section{RESULTS AND DISCUSSION}

Table 1 shows the results of surface roughness for all groups. According to the averages, all the parameters decreased with the proportion of rhododendron mixed. The ANOVA and Duncan's multiple range tests showed these changes to be significant. 
Table 1. Surface Roughness ( $\mu \mathrm{m})$ Values of Medium Density Fiberboard (MDF) Panels.

\begin{tabular}{|c|c|c|c|c|c|}
\hline \multirow{2}{*}{$\begin{array}{l}\text { Panel } \\
\text { Group }\end{array}$} & \multirow{2}{*}{ Unit } & $\mathrm{R}_{\mathrm{a}}$ & $\mathrm{R}_{z}$ & $\mathrm{R}_{\mathrm{q}}$ & $\mathrm{R}_{\mathrm{y}}$ \\
\hline & & $\mu \mathrm{m}$ & $\mu \mathrm{m}$ & $\mu \mathrm{m}$ & $\mu \mathrm{m}$ \\
\hline \multirow{5}{*}{$\begin{array}{c}\text { Industrial } \\
\text { Furnish }\end{array}$} & Avg. & $9.8 \mathrm{~A}$ & $66.0 \mathrm{~A}$ & $12.4 \mathrm{~A}$ & $82.3 \mathrm{~A}$ \\
\hline & $\pm s$ & 1.3 & 8.6 & 1.7 & 13.4 \\
\hline & $s^{2}$ & 1.8 & 73.7 & 2.7 & 179.3 \\
\hline & $\mathrm{V}$ & 13.8 & 13.0 & 13.3 & 16.3 \\
\hline & $\mathrm{N}$ & 40 & 40 & 40 & 40 \\
\hline \multirow{5}{*}{$100 \%$} & Avg. & $7.2 \mathrm{~B}$ & $49.2 \mathrm{~B}$ & $9.2 \mathrm{~B}$ & $62.8 \mathrm{~B}$ \\
\hline & $\pm s$ & 0.9 & 4.9 & 1.2 & 10.3 \\
\hline & $s^{2}$ & 0.8 & 23.8 & 1.3 & 105.9 \\
\hline & V & 12.8 & 9.9 & 12.5 & 16.4 \\
\hline & $\mathrm{N}$ & 40 & 40 & 40 & 40 \\
\hline \multirow{5}{*}{$75 \%$} & Avg. & 7.0 CDE & 46.3 CDE & 8.8 CDE & $62.5 \mathrm{CDE}$ \\
\hline & $\pm s$ & 1.0 & 6.9 & 1.3 & 9.6 \\
\hline & $s^{2}$ & 1.1 & 47.3 & 1.7 & 92.5 \\
\hline & V & 14.9 & 14.9 & 14.8 & 15.4 \\
\hline & $\mathrm{N}$ & 40 & 40 & 40 & 40 \\
\hline \multirow{5}{*}{$50 \%$} & Avg. & $3.8 \mathrm{DE}$ & $30.5 \mathrm{DE}$ & $5.0 \mathrm{DE}$ & $38.5 \mathrm{DE}$ \\
\hline & $\pm s$ & 0.9 & 5.6 & 1.0 & 7.3 \\
\hline & $s^{2}$ & 0.8 & 31.6 & 1.2 & 53.7 \\
\hline & V & 24.3 & 18.5 & 21.6 & 19.0 \\
\hline & $\mathrm{N}$ & 40 & 40 & 40 & 40 \\
\hline \multirow{5}{*}{$25 \%$} & Avg. & $2.9 \mathrm{E}$ & $26.0 \mathrm{E}$ & $3.9 \mathrm{E}$ & $32.4 \mathrm{E}$ \\
\hline & $\pm s$ & 0.5 & 3.4 & 0.6 & 5.7 \\
\hline & $s^{2}$ & 0.2 & 11.9 & 0.4 & 32.3 \\
\hline & V & 16.3 & 13.2 & 15.9 & 17.5 \\
\hline & $\mathrm{N}$ & 40 & 40 & 40 & 40 \\
\hline
\end{tabular}

Avg $=$ average; $\pm s=$ standard deviation; $\mathrm{s}^{2}=$ variance. $\mathrm{V}=$ coefficient of variation $\mathrm{N}=$ number of samples used in each test.

Homogeneity groups: same letters in each column indicate that there is no statistical difference between the samples according to the Duncan's multiply range test at $\mathrm{P}<0: 05$. Comparisons were done between the each control and its test.

It is evident from table 1 that the surface roughness values decrease with a decreasing mixture of rhododendron fibers under the conditions in this study. The maximum decrease for all parameters was recorded at a mix the $25 \%$ rhododendron fibers were mixed with oak and pine to manufacture the panels in addition to board produced $100 \%$ of each species.

The panels made from $25 \%$ rhododendron wood had the lowest average surface roughness value (2.929) while panels containing $100 \%$ rhododendron wood had the highest. Average surface roughness was higher for control samples containing more industrial furnish. $R_{z}, R_{q}$ and $R_{y}$ parameters had similar trends to the $\mathrm{R}_{\mathrm{a}}$ values. Increasing the mixing ratio in the mixture negatively affected the surface roughness parameters of the panels. 
Table 2 shows the levels of decreases in surface roughness values in the MDF Panels with decreased mixed of rhododendron biomass.

Table 2. Decreasing Based on Mixing Ratios in the Panels.

\begin{tabular}{ccccc}
\hline Panel Type & $\mathrm{R}_{\mathrm{a}}$ & $\mathrm{R}_{\mathrm{z}}$ & $\mathrm{R}_{\mathrm{q}}$ & $\mathrm{R}_{\mathrm{y}}$ \\
\cline { 2 - 5 } & $\%$ & $\%$ & $\%$ & $\%$ \\
\hline $100 \%$ & 26.6 & 25.4 & 25.8 & 23.7 \\
$75 \%$ & 28.9 & 29.8 & 29.0 & 24.0 \\
$50 \%$ & 61.3 & 53.8 & 59.9 & 53.2 \\
$25 \%$ & 70.0 & 60.5 & 68.5 & 60.6 \\
\hline
\end{tabular}

The initial results of this study suggest four roughness parameters can be used to quantify and improve roughness properties of samples for further manufacturing steps. For the direct painting and other surface finishing treatments of MDF to be successful, especially in furniture industry, the surfaces must to be smooth, stable, and not highly absorbent.

In general, the results of this study describing the effect of mixed ratios of two fiber types on the panel are comparable to the findings of other studies. Nemli et al. (2005) found that raw material type affected surface roughness of particleboard. Also, an increase in shelling ratio, panel density, and press pressure improved the surface roughness of particleboard. Buyuksari et al. (2010) found that the average $\mathrm{R}_{\mathrm{a}}$ values of the panels increased as a greater ratio of pine cone was added to the mixture. Panels made from $100 \%$ wood particles had the smoothest surface $(9.77 \mu \mathrm{m})$, and the roughest surface $(15.50 \mu \mathrm{m})$ was obtained from the panels containing $50 \%$ pine cone. The $\mathrm{R}_{\mathrm{y}}$ and $\mathrm{R}_{\mathrm{z}}$ parameters of panels had similar trends to the Ra values. These values also increased with increasing the pine cone ratio in the mixture.

Surface roughness is a function of raw material characteristics, species, particle size and distribution and manufacturing variables, press parameters, resin content, face layer densification, and sanding process of the panels. Differences in the average surface roughness of the produced particleboards were most likely due to the morphological properties of wood.

It is recommended that the surface roughness values of the panels made from rhododendron wood be improved by sanding and by increasing panel density, shelling ratio, and pres pressure.

The CA values of the samples were maximum at the beginning of the tests. The angles decreased with increasing time. The values were minimum at the end of the tests (at 30rd second). As seen from table 3, the CA values of the panels made from rhododendron wood significantly increased with increasing mix ratios of rhododendron fibers. The results acquired in this study also indicate the wettability property of the panels decreased with the mixed ratios of rhododendron fibers. The $\mathrm{CA}$ values were greater in the case of the panels containing rhododendron fibers compared to those of the control panels. This change of wettability could have significant consequences on the use of the material, in particular for the adhesion of paints and coatings. Wettability of the MDF panels can provide good information on their ability to bond (Hakkou et al. 2005). There is evidence about the positive relationship between wood wettability and adhesion. When contact angle is zero, perfect wetting of a surface occurs. Contact angle is a useful index of adhesive effectiveness (Ayrilmış and Winandy 2009). 
Table 3. Contact Angle Results of the Panels.

\begin{tabular}{ccc}
\hline & \multicolumn{2}{c}{ Wettability } \\
\cline { 2 - 3 } Groups & CA ( $)$ & Duncan's grouping \\
\hline Control & $90.54(17.03)$ & $\mathrm{de}$ \\
$100 \%$ & $117.91(10.41)$ & $\mathrm{a}$ \\
$75 \%$ & $99.38(12.96)$ & $\mathrm{cde}$ \\
$50 \%$ & $99.47(18.79)$ & $\mathrm{bde}$ \\
$25 \%$ & $88.14(16.61)$ & $\mathrm{e}$ \\
\hline
\end{tabular}

Homogenous groups: letters in each column indicate groups that are statistically different according to Duncan's multiple range test at $\mathrm{P}<0.05$. Comparisons were between each control and its test.

\section{CONCLUSIONS}

The results of this work showed that a stylus profilometer can be used to evaluate surface roughness variations of the panels. The average $R_{a}$ value of the produced panels increased with increasing the rhododendron fiber ratio in the mixture.

The increase in the surface roughness of the panels should be considered if the MDF panels containing rhododendron fibers are used in manufacturing overlaid panels for the furniture industry.

It was concluded that the MDF panels made from rhododendron biomass had poor wettability performance. The results also indicate the wettability property of the panels decreased as the rhododendron wood ratio increased.

Finally, it could be suggested that rhododendron biomass could be used an alternative raw material for MDF manufacturing so that sustainable forest management could be achieved.

\section{REFERENCES}

Akbulut, T.; Hiziroglu, S.; Ayrılmış, N. 2000. Surface Absorption, Surface Roughness, and formaldehyde Emission of Turkish Medium Density Fiberboard. Forest Prod J. 50(6): 45-48.

Akgul, M.; Tozluoglu, A. 2008. Utilizing peanut husk (Arachis hypogaea L.) in the manufacture of medium-density fiberboards. Bioresource Technol 99(13): 5590-5594.

Akgul, M.; Camlibel, O. 2008. Manufacture of medium density fiberboard (MDF) panels from rhododendron (R. ponticum L.) biomass. Build. Environ. 43(4): 438-443.

Aydin, I.; Colakoglu G. 2002. The effects of veneer drying temperature on wettability, surface roughness and some properties of plywood. In: Proceedings of the sixth panel products symposium, 9-11 October 2002, Llandudno, Wales, UK: 60-70.

Aydin, I. 2004. Activation of wood surfaces for glue bonds by mechanical pre-treatment and its effects on some properties of veneer surfaces and plywood panels. Applied Surface Science 233(1-4): 268- 274.

Aydin, I.; Colakoglu, G.; Hiziroglu, S. 2006. Surface characteristics of spruce veneers and shear 
strength of plywood as a function of log temperature in peeling process. Int J. Solids Struct. 43(20): 6140-6147.

Ayrılmış, N. 2008. Effect of compression wood on dimensional stability of medium density fiberboard. Silva Fennica 42(2): 285-293.

Ayrılmış, N.; Dundar, T.; Candan, Z.; Akbulut, T. 2009. Wettability of fire retardant treated laminated veneer lumber (LVL) manufactured from veneers dried at different temperatures. Bioresources 4(4): 1536- 1544.

Ayrılmış, N.; Winandy, J. E. 2009. Effects of Post Heat-Treatment on Surface Characteristics and Adhesive Bonding Performance of Medium Density Fiberboard. Materials and Manufacturing Processes 24(5): 594-599.

Buyuksari, U.; Avci, E.; Ayrılmış, N.; Akkilic, H. 2010. Effect of pine cone ratio on the wettability and surface roughness of particleboard. BioRes. 5(3): 1824-1833.

Candan, Z.; Hiziroglu, S.; McDonald, AG. 2010. Surface quality of thermally compressed Douglas fir veneer. Mater Design 31(7): 3574-3577.

Candan, Z.; Buyuksari, U.; Unsal, O.; Korkut, S. 2012. Wettability and surface roughness of thermally modified plywood panels. Ind Crop Prod. 36(1): 434-436.

Chow, P.; Zhao, L. 1992. Medium Density Fiberboard Made From Phenolic Resin And Wood Residues of Mixed Species. Forest Prod J. 42(10): 65-67.

DIN, Deutsches Institut für Norming. 1990. Determination of values of surface roughness parameters Ra, Rz, Rmax using electrical contact (stylus) instruments, concepts and measuring conditions. DIN 4768. Berlin, Germany.

Dundar, T.; Ayrılmış, N.; Candan, Z. 2008. Evaluation of surface roughness of laminated veneer lumber (LVL) made from beech veneers treated with various fire retardants and dried at different temperatures. Forest Prod J. 58(1/2): 71-76.

Esen, D.; Yildiz, O.; Kulac, S.; Sarginci, M. 2006. Control of Rhododendron spp. in Turkish Black Sea Region. Forestry 79(2): 177-184.

FAO, 2009. Faostat. [on line] <http://faostat.fao.org/site/628/DesktopDefault.aspx?PageID=628> [consulted date: May 2011]

Fengel, D.; Wegener, G. 1989. Wood: Chemistry, Ultrastructure, Reactions. Walter De Gruyter, Berlin-Germany. 600p.

Goker, Y.; Demetci, E.; As, N. 1997. Research on surface smoothness applied to wood products. XI World Forestry Congress, Antalya, Turkey, p. 51-53.

Hakkou, M.; Pétrissans, M.; Zoulalian, A.; Gérardin, P. 2005. Investigation of wood wettability changes during heat treatment on the basis of chemical analysis. Polym Degrad Stabil. 89(1): 1-5.

Hiziroglu, S.S. 1996. Surface Roughness Analysis of Wood Composites: A Stylus Method. Forest Prod J. 46(7/8): 67-72. 
Hiziroglu, S.; Graham, S. 1998. Effect of press closing time and target thickness on surface roughness of particleboard. Forest Prod J. 48: 50-54.

Hiziroglu, S. 2005. Surface roughness evaluation of medium density fiberboard (MDF) using stylus and pneumatic methods. Holz Roh Werkst. 63(1): 81-82.

Hiziroglu, S.; Suzuki, S. 2007. Evaluation of surface roughness of commercially manufactured particleboard and medium density fiberboard in Japan. J Mater Process Tech 184(1-3): 436-440.

ISO, International Organization for Standardization. 1997. Geometrical product specifications (GPS)- surface texture: profile method-terms, definitions, and surface texture parameters. ISO 4287. Geneva, Switzerland.

Lu, Z. 2003. Chemical Coupling in Wood-Polymer Composites, Ph.D. Thesis, Louisiana State University, Agricultural and Mechanical College. 257 p.

Mitutoyo surface roughness tester, 2002. Mitutoyo Surftest SJ-301. Product no. 99MBB035A 1. Series No. 178, Mitutoyo Corporation, 20-1, Sakado 1-chome, Takatsu-ku, Kawasaki, Kanagawa 213-0012, Japan.

Mummery, L. 1993. Surface texture analysis. The handbook. Muhlhausen, Germany: Hommelwerke, 106p.

Nemli, G.; Ozturk, I.; Aydin, A. 2005. Some of the parameters influencing surface roughness of particleboard. Building and Environment 40(10):1337-1340.

Peters, C.; Cumming, J.D. 1970. Measuring wood surface smoothness: a review. Forest Prod J. 20(12): 3-40.

Peters, C.; Mergen, A. 1971. Measuring wood surface smoothness: a proposed method. Forest Prod J. 21(7): 28-30.

Stumbo, D.A. 1963. Surface texture measurement. Forest Prod J. 13(6): 299-304.

TS EN 326-1, 1999. Wood- Based panels- Sampling, cutting and inspection- Part 1: Sampling test pieces and expression of test results, TSE, Ankara, Turkey.

TS EN 325, 1999. Wood-Based panels- Determination of dimensions of test pieces, TSE, Ankara, Turkey.

Unsal, O.; Candan, Z.; Buyuksari, U.; Korkut, S.; Babiak M. 2010. Effects of thermal modification on surface characteristics of OSB panels. Wood Research 55(4): 51- 58.

Unsal, O.; Candan, Z.; Korkut, S. 2011. Wettability and roughness characteristics of modified wood boards using a hot-press. Ind Crop Prod. 35(1): 287-294.

Xu, W.; Suchland, O. 1998. Variability of Particleboard Properties from Single-And MixedSpecies processes. Forest Prod J. 48(9): 68-74.

Yildiz, O.; Esen, D.; Sarginci, M.; Guler, M. 2005. Effects of vegetation management practices on long-term site productivity in Eastern Beech (Fagus orientalis, Lipsky). X. European Ecological Congress. Organized by European Ecological Federation and Turkish Ecological Society. Ege University Centre for Environmental Studies, Kusadas1-Turkey. 259p. 
